\title{
Variability of Fatty Acids Composition of Wild Sumac (Rhus coriaria L.) Fruit
}

\author{
Nayebpour N (M.Sc.) ${ }^{1}$, Asadi-Gharneh HA (Ph.D.) ${ }^{1 *}$ \\ 1- Department of Horticulture, Faculty of Agriculture, Isfahan (Khorasgan) Branch, \\ Islamic Azad University, Isfahan, Iran \\ *Corresponding author: Department of Horticulture, Faculty of Agriculture, Isfahan \\ (Khorasgan) Branch, Islamic Azad University, Isfahan, Iran \\ Tel: +98-913-1282250, Fax: +98-31-35354060 \\ E-mail: h.asadi@khuisf.ac.ir
}

Received: 26 Feb. 2019

Accepted: 28 May 2019

doi: $10.29252 / \mathrm{jmp} .3 .71 .118$

Abstract

Background: Sumac (Rhus coriaria $L$.) belongs to Anacardiaceae family. The dried and powdered fruits are used as a food flavoring and medicinal plant.

Objective: In this study, variability of fatty acid composition in some wild sumac fruits were investigated.

Method: The samples were collected from their natural origins in central parts of Iran; Isfahan and Markazi province in the September to October, 2016. The morphological characters of fresh fruits were measured. Also oil content and profile of fatty acids composition were measured.

Results: Results indicated that there are significant differences between morphological characteristics, oil percent and fatty acids compositions of wild sumac fruit populations. The range of oil percent of Iranian sumac population was $9.22 \%$ to $15.33 \%$. The major oil quantity contained unsaturated fatty acids $(64.75 \%-74.08 \%)$ followed by saturated fatty acids $(25.84 \%-35.13 \%)$. Among saturated fatty acids, palmitic was evaluated as the highest value (21.36- 29.79 \%) while the most unsaturated fatty acids were oleic acid (36.65- $44.74 \%)$ and linoleic acid (22.62- 33.48 \%). Also, soil and geographical characteristics show significant relationship with fatty acids quantity in this study.

Conclusion: According to our results concluded that the differences between fatty acids of sumac fruits may be related to the growth conditions like soil and geographical characteristics. Also, this study demonstrates that sumac can be a good source of fatty acids and could be useful for human nutrition.

Keywords: Sumac, Linolenic acid, Oleic acid, Saturated fatty acids, Unsaturated fatty acids 


\section{Introduction}

Sumac (Rhus coriaria L.) is a wild perennial medicinal plant belongs to Anacardiaceae family. This name is originated from "sumaga" in Syriac, it means red [1]. Sumac grows wild especially in the Mediterranean bordering countries, South Europe, North Africa, Afghanistan, and Iran [2]. The wild sumac plant reaches 3-4 $\mathrm{m}$ in height [3]. Sumac ( $R$. coriaria L.) is the only species in the Rhus genus occurring in Iran [4]. It is growing naturally (wild) in the northern regions of Iran [5]. In addition, central region of Iran is covered by wild sumac population (Figure 1).

The ripe fruits are round, villous and reddish brown drupe with one seed that contains tannins, essential oils, several organic acids, anthocyanin and fixed oil [6]. The dried drupes are usually ground to produce a tangy purple spice [7]. Also, in Iranian herbal medicine, sumac has been accepted as antiseptic and also food flavoring agent traditionally [5].

Some researches such as microelement contents [8], physico-chemical properties [1,9, 10] phytochemistry, pharmacological properties [11] and fatty acid composition [5, 12] have been reported in sumac varieties. Among these characters, fatty acids are essential for human beings. Also, supplying fatty acids components should be considered in different resources [8]. Sumac fruits are rich in oils and fatty acids so could be valuable for using in human nutrition. Palmitic, oleic and linoleic acids are found as the major components of sumac oil [8, 13]. Differences in fatty acid composition among four sumac cultivars grown in Turkey were reported [14]. In another research, the predominant fatty acids in sumac fruit are linoleic, oleic, palmitic, stearic and linolenic acid [15].

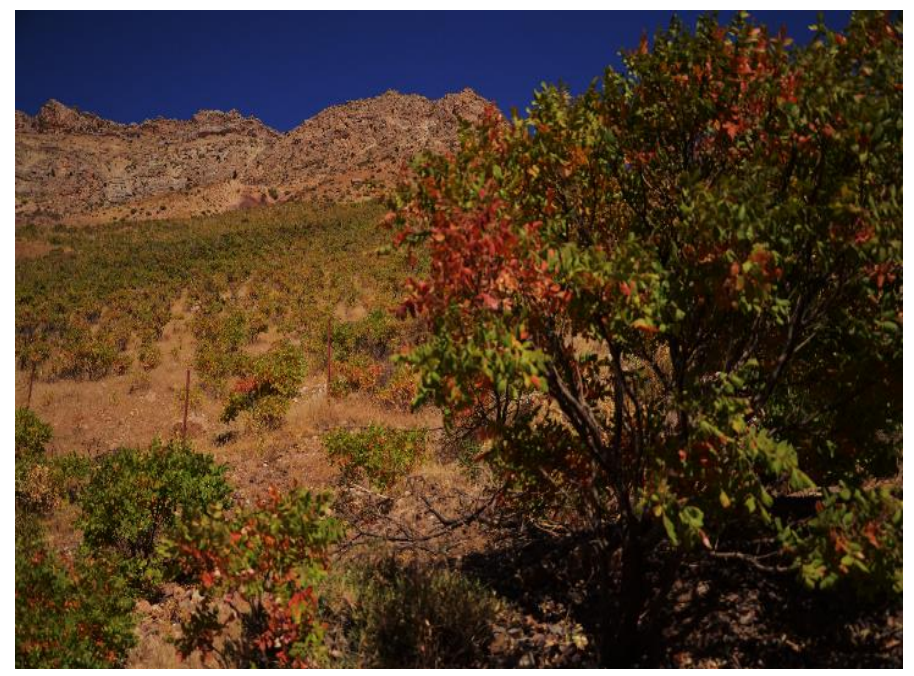

Figure 1- Sumac trees in the pashandegan region (Isfahan province) 
The aim of this study was to evaluate morphological characters and fatty acids composition of Iranian wild sumac fruit, existed in central parts of Iran. Also the physical and chemicals soil properties of those collected population were analyzed in relation to fruit biochemical compositions of wild sumac populations.

\section{Materials and Methods}

The samples were collected from their natural origins in central parts of Iran; Isfahan and Markazi province in the September to October, 2016. The names of populations come from sample collection (Pashandegan, Baghestan, Yahya- Abad, Torgh, Firizhand, and Malmir). All samples were collected from their native origin and there were no treatments on them. In each region, 20 sumac trees were randomly selected and the fruit clusters (bobs) of all chosen trees were collected. Then samples were stored separately in $4{ }^{\circ} \mathrm{C}$ on dry ice and transferred to laboratory in the College of Agriculture, Isfahan (Khorasgan) Branch, Islamic Azad University, Isfahan, Iran for analysis.

The geographical characteristics includes: latitude, longitude and altitude of the regions were determined using the GPS. Also the factors that Influence climate such as; the average annual temperature $\left({ }^{\circ} \mathrm{C}\right)$, the average annual humidity (\%), the average annual rainfall $(\mathrm{mm})$, the average annual sunshine hours (h) and the average wind speed $\left(\mathrm{Kmh}^{-1}\right)$ for each region were assessed (Table 1).

\section{Determination of soil properties}

The physical and chemicals of soil properties in the studied regions were determined using the standard laboratory procedure and presented in Table 2. After transferring the samples to the laboratory, they were air-dried and passed through a $2 \mathrm{~mm}$ sieve. Soil samples were analyzed to determine particle-size distribution (hydrometer method), $\mathrm{pH}$ (measure of the acidity or basicity), EC (saturated extract at $25{ }^{\circ} \mathrm{C}$ ), soil reaction (saturated point), calcium-carbonate equivalent $\left(\mathrm{CaCo}_{3}\right)$, OC (organic carbon) Also, total nitrogen $(\mathrm{N})$, phosphor $(\mathrm{P})$, potassium $(\mathrm{K})$ and Sodium $(\mathrm{Na})$, in saturation extract were assessed [16].

\section{Determination of morphological characteristics}

The morphological characters of fresh sample related to the weight were measured with an electronic caliper with $0.001 \mathrm{~g}$ accuracy. Seed, pericarp and fruit weight was determined by weighting sample of 100 seeds, pericarps and fruits and averages were calculated. The fruit cluster length was measured manually by a ruler.

\section{Determination of fatty acid compositions}

We extracted $10 \mathrm{~g}$ of fresh fruit with petroleum ether for $6 \mathrm{~h}$ in Soxhlet apparatus [17]. Fatty acids were converted into their methyl esters according to the following method. At first $0.5 \mathrm{~g}$ of extracted oil were placed in glass screw-cap vials, $1 \mathrm{ml}$ of $1 \mathrm{~N}$ 
Table 1- Location and climatic information of six regions that samples were collected

\begin{tabular}{lcccccc}
\hline & Pashandegan & Baghestan & Yahya-Abad & Torgh & Firizhand & Malmir \\
\hline Latitude (N) & $32^{\circ} 48^{\prime}$ & $33^{\circ} 21^{\prime}$ & $33^{\circ} 20^{\prime}$ & $33^{\circ} 23^{\prime}$ & $33^{\circ} 31^{\prime}$ & $34^{\circ} 45^{\prime}$ \\
Longitude (E) & $54^{\circ} 70^{\prime}$ & $51^{\circ} 27^{\prime}$ & $45^{\circ} 83^{\prime}$ & $51^{\circ} 46^{\prime}$ & $51^{\circ} 42^{\prime}$ & $49^{\circ} 50^{\prime}$ \\
Altitude (m) & 2312 & 2090 & 2084 & 2219 & 2273 & 1870 \\
The average annual temperature (C) & 11.71 & 17.95 & 17.08 & 17.08 & 17.08 & 17.80 \\
The average annual humidity (\%) & 35.44 & 41.21 & 35.27 & 35.27 & 35.27 & 35.27 \\
The average annual rainfall (mm) & 42.17 & 26.51 & 15.07 & 15.07 & 15.07 & 15.07 \\
The average annual sunshine hours (h) & 257.13 & 258.21 & 257.77 & 257.77 & 257.77 & 257.77 \\
Average wind speed (kmh ${ }^{-1}$ ) & 2.31 & 3.80 & 3.30 & 3.30 & 3.30 & 3.30 \\
\hline
\end{tabular}

Table 2- Physical and chemical properties of soil in studied regions

\begin{tabular}{|c|c|c|c|c|c|c|}
\hline & \multirow[b]{2}{*}{ Torgh } & \multirow[b]{2}{*}{ Firizhand } & \multicolumn{2}{|c|}{ Regions } & \multirow[b]{2}{*}{ Yahya-Abad } & \multirow[b]{2}{*}{ Malmir } \\
\hline & & & Baghestan & Pashandegan & & \\
\hline soil texture & loam & loam & loam & clay & sandy clay loam & sandy loam \\
\hline $\mathrm{pH}$ & 7.8 & 7.9 & 7.5 & 7.8 & 8.1 & 7.3 \\
\hline $\mathrm{EC}(d s / m)$ & 1.1 & 1.8 & 1.8 & 1.0 & 1.7 & 0.7 \\
\hline S.P $(\%)$ & 65.89 & 89.02 & 61.65 & 60.89 & 45.33 & 40.02 \\
\hline O.C $(\%)$ & 3.63 & 8.78 & 4.43 & 4.57 & 3.22 & 4.30 \\
\hline $\mathrm{CaCo}_{3}(\%)$ & 28.4 & 14.6 & 29.3 & 9.2 & 19.8 & 10.3 \\
\hline $\mathrm{N}(\%)$ & 0.18 & 0.53 & 0.20 & 0.28 & 0.18 & 0.19 \\
\hline P Av. (mg/kg) & 60 & 100 & 37 & 34 & 96 & 34 \\
\hline K Av. (mg/kg) & 170 & 190 & 176 & 180 & 132 & 140 \\
\hline $\mathrm{Na}(m e / l)$ & 740 & 820 & 720 & 700 & 965 & 931 \\
\hline
\end{tabular}

$\mathrm{MeOH} / \mathrm{HCL}$ was added, and the mixture was vortexed briefly, then incubated at $85{ }^{\circ} \mathrm{C}$ for 24 $h$ to ensure complete derivatization. After removal from the oven, vials were cooled to room temperature, then $250 \mu \mathrm{l}$ of $0.9 \% \mathrm{KCl}$ was added, followed by $1600 \mu \mathrm{l}$ of hexane. The mixture was briefly vortexed, and after phase separation, an aliquot of upper phase which contained fatty acids to methyl esters was collected for analysis [18]. All chemicals and reagents used were of analytical grade and $95 \%$ to $98 \%$ purity (Merck, Germany).

A gas chromatography (GC) (Agilent Technologies $6890 \mathrm{~N}$ GC system), equipped with a flame-ionization detector (GC-FID) was used. GC analysis is performed under the following conditions. Capillary column Hp- 88 $(100 \mathrm{~m} \times 0.25 \mathrm{~mm} \times 0.2 \mu \mathrm{m})$; the carrier gas was nitrogen, with purity of $99.9 \%$ and the column flow rate was $1 \mathrm{ml} / \mathrm{min}$. The Oven temperature was kept at $100^{\circ} \mathrm{C}$ for $5 \mathrm{~min}$ and increased to $240^{\circ} \mathrm{C}$ at a rate of $4^{\circ} \mathrm{C} / \mathrm{min}$ and maintained at $240^{\circ} \mathrm{C}$ for 30 minutes. The temperature of the injection port and detector were $260^{\circ} \mathrm{C}$ and $250^{\circ} \mathrm{C}$, respectively. Oil samples $(2 \mu \mathrm{L})$ were injected automatically.

\section{Data analysis}

The obtained statistical parameters were analyzed by SAS software. In discussing our results, whenever we compare different characteristics, we apply Duncan multiple range test at $5 \%$ probability level. Cluster analysis was also carried out using SPSS statistical software (version. 21.0 for Widows). 


\section{Results}

\section{Morphological and biochemical assessment}

The analysis of variance of morphological characteristics of wild sumac fruit populations demonstrated the significant differences among them (Table 3). The comparison of means indicated that Baghestan population $(2.27 \mathrm{~g})$ and Malmir population (1.05 g) had the highest and lowest amount of 100 fruits weight, respectively. The range of pericarp weight (average of 100 pericarps) was measured from $0.55 \mathrm{~g}$ in Malmir population to $1.19 \mathrm{~g}$ in Firizhand. The highest $(1.09 \mathrm{~g})$ and the lowest $(0.50 \mathrm{~g})$ amount of 100 seeds weight was measured in Baghestan and Malmir populations, respectively. In terms of fruit cluster length, the Firizhand population (11.81 $\mathrm{cm})$ and Torgh population $(10.93 \mathrm{~cm})$ had the highest value while the Malmir population $(6.12 \mathrm{~cm})$ had the lowest.

The statistical analysis of fatty acids of sumac populations including the average, the minimum, the maximum, standard deviation and coefficient of variation of Caprylic acid (C8:0), Capric acid (C10:0), Myristic acid (C14:0), Palmitic acid (C16:0), Stearic acid (C18:0), Arachidic acid (C20:0), Palmitoleic acid (C16:1), Oleic acid (C18:1), Linoleic acid (C18:2), Linolenic acid (C18:3), Gadolenic acid (C20:1), Eicosatrienoic acid (C20:3) are presented in Table 4.

The range of oil percent of Iranian sumac population was $9.22 \%$ (Malmir) to $15.33 \%$ (Yahya- Abad, Table 5 and Figure 3). Analysis of fatty acid compositions of wild sumac populations revealed the significant differences between them. Twelve fatty acids composition including; 6 saturated and 6 unsaturated fatty acids were identified from all wild fruit sumac populations (Figure 2) and significant differences were observed among them. In current study the major oil quantity contained unsaturated fatty acids (64.75\%- 74.08\%) followed by saturated fatty acids $(25.84 \%$ $35.13 \%$, Table 5, Figure 3). The predominant

Table 3- Means comparison of morphological characteristics in Iranian sumac populations

\begin{tabular}{|c|c|c|c|c|c|c|}
\hline & Pashandegan & Baghestan & Torgh & Yahya- Abad & Firizhand & Malmir \\
\hline 100 fruits weight $(\mathrm{g})$ & $1.80^{\mathrm{c}}$ & $2.27^{\mathrm{a}}$ & $1.88^{\mathrm{b}}$ & $2.21^{\mathrm{a}}$ & $2.20^{\mathrm{a}}$ & $1.05^{\mathrm{d}}$ \\
\hline 100 pericarps weight $(\mathrm{g})$ & $1.07^{\mathrm{a}}$ & $1.18^{\mathrm{a}}$ & $0.94^{b}$ & $1.15^{\mathrm{a}}$ & $1.19^{\mathrm{a}}$ & $0.55^{\mathrm{c}}$ \\
\hline 100 seeds weight $(\mathrm{g})$ & $0.73^{\mathrm{e}}$ & $1.09^{\mathrm{a}}$ & $0.94^{\mathrm{d}}$ & $1.06^{\mathrm{b}}$ & $1.01^{\mathrm{c}}$ & $0.50^{\mathrm{f}}$ \\
\hline Fruit cluster length $(\mathrm{cm})$ & $9.32^{\mathrm{bc}}$ & $9.13^{\mathrm{bc}}$ & $10.93^{\mathrm{ab}}$ & $7.76^{\mathrm{cd}}$ & $11.81^{\mathrm{a}}$ & $6.12^{\mathrm{d}}$ \\
\hline
\end{tabular}

Table 4- The statistical analysis of fatty acids in sumac fruit

\begin{tabular}{llllll}
\hline Fatty acids & Min. & Max. & Mean & SD & CV \\
\hline Caprylic acid (C8:0) & 0.01 & 0.90 & 0.08 & 0.21 & 23.80 \\
Capric acid (C10:0) & 0.05 & 0.31 & 0.18 & 0.07 & 16.82 \\
Myristic acid (C14:0) & 0.21 & 0.66 & 0.34 & 0.15 & 8.67 \\
Palmitic acid (C16:0) & 21.36 & 29.79 & 24.94 & 3.02 & 0.59 \\
Stearic acid (C18:0) & 2.31 & 3.61 & 2.74 & 0.43 & 0.57 \\
Arachidic acid (C20:0) & 0.61 & 1.57 & 1.13 & 0.34 & 2.98 \\
Palmitoleic acid (C16:1) & 0.28 & 0.58 & 0.43 & 0.08 & 5.65 \\
Oleic acid (C18:1) & 36.65 & 44.74 & 40.45 & 3.20 & 0.06 \\
Linoleic acid (C18:2) & 22.62 & 33.48 & 27.22 & 4.32 & 0.14 \\
Linolenic acid (C18:3) & 1.22 & 2.70 & 1.65 & 0.39 & 7.87 \\
Gadolenic acid (C20:1) & 0.12 & 0.28 & 0.19 & 0.05 & 16.07 \\
Eicosatrienoic acid (C20:3) & 0.28 & 0.68 & 0.49 & 0.14 & 6.93 \\
\hline
\end{tabular}






Figure 2- The chromatograph related to the analysis of fatty acids of Baghestan region 
Table 5- Oil percent, saturated and unsaturated fatty acids in sumac fruits

\begin{tabular}{|c|c|c|c|c|c|c|}
\hline Fatty acid composition (\%) & Pashandegan & Baghestan & Torgh & Yahya- Abad & Firizhand & Malmir \\
\hline Oil Percent & $9.33^{\mathrm{c}}$ & $14.67^{\mathrm{ab}}$ & $12.67^{b}$ & $15.33^{\mathrm{a}}$ & $9.33^{\mathrm{c}}$ & $9.20^{\mathrm{ab}}$ \\
\hline Total unsaturated fatty acids (UFA) & $73.68^{\mathrm{b}}$ & $70.80^{\mathrm{d}}$ & $72.22^{\mathrm{c}}$ & $66.94^{\mathrm{e}}$ & $74.08^{\mathrm{a}}$ & $64.75^{\mathrm{f}}$ \\
\hline Total saturated fatty acids (SFA) & $26.15^{\mathrm{e}}$ & $28.88^{c}$ & $27.61^{\mathrm{d}}$ & $32.74^{\mathrm{b}}$ & $25.84^{\mathrm{e}}$ & $35.13^{\mathrm{a}}$ \\
\hline Mono unsaturated fatty acids (MUFA) & $38.64^{\mathrm{d}}$ & $45.30^{\mathrm{a}}$ & $44.68^{\mathrm{b}}$ & $41.81^{\mathrm{c}}$ & $38.64^{\mathrm{d}}$ & $37.29^{\mathrm{e}}$ \\
\hline Poly unsaturated fatty acids (PUFA) & $35.04^{\mathrm{b}}$ & $25.50^{\mathrm{d}}$ & $27.54^{\mathrm{c}}$ & $25.13^{\mathrm{e}}$ & $35.44^{\mathrm{a}}$ & $27.46^{\mathrm{c}}$ \\
\hline UFA to SFA ratio & $2.81^{\mathrm{b}}$ & $2.45^{\mathrm{d}}$ & $2.61^{\mathrm{c}}$ & $2.04^{\mathrm{c}}$ & $2.86^{\mathrm{a}}$ & $1.84^{\mathrm{f}}$ \\
\hline Caprylic acid (C8:0) & $0.02^{\mathrm{b}}$ & $0.02^{\mathrm{b}}$ & $0.02^{\mathrm{b}}$ & $0.02^{\mathrm{b}}$ & $0.01^{\mathrm{b}}$ & $0.37^{\mathrm{a}}$ \\
\hline Capric acid (C10:0) & $0.28^{\mathrm{a}}$ & $0.08^{\mathrm{d}}$ & $0.18^{\mathrm{bc}}$ & $0.23^{\mathrm{ab}}$ & $0.17^{\mathrm{c}}$ & $0.13^{\mathrm{cd}}$ \\
\hline Myristic acid (C14:0) & $0.23^{\mathrm{c}}$ & $0.24^{\mathrm{c}}$ & $0.26^{\mathrm{c}}$ & $0.37^{\mathrm{b}}$ & $0.27^{\mathrm{c}}$ & $0.64^{\mathrm{a}}$ \\
\hline Palmitic acid (C16:0) & $22.53^{\mathrm{e}}$ & $24.65^{\mathrm{c}}$ & $23.56^{\mathrm{d}}$ & $27.75^{\mathrm{b}}$ & $21.38^{\mathrm{f}}$ & $29.75^{\mathrm{a}}$ \\
\hline Stearic acid (C18:0) & $2.32^{\mathrm{f}}$ & $2.66^{\mathrm{c}}$ & $2.44^{\mathrm{e}}$ & $2.84^{\mathrm{b}}$ & $2.56^{\mathrm{d}}$ & $3.60^{\mathrm{a}}$ \\
\hline Arachidic acid (C20:0) & $0.77^{\mathrm{e}}$ & $1.23^{\mathrm{c}}$ & $1.15^{\mathrm{d}}$ & $1.53^{\mathrm{a}}$ & $1.45^{\mathrm{b}}$ & $0.64^{\mathrm{f}}$ \\
\hline Palmitoleic acid (C16:1) & $0.55^{\mathrm{a}}$ & $0.40^{\mathrm{b}}$ & $0.46^{\mathrm{b}}$ & $0.43^{\mathrm{b}}$ & $0.30^{\mathrm{c}}$ & $0.43^{\mathrm{b}}$ \\
\hline Oleic acid (C18:1) & $37.95^{\mathrm{e}}$ & $44.74^{\mathrm{a}}$ & $44.07^{\mathrm{b}}$ & $41.16^{\mathrm{c}}$ & $38.10^{\mathrm{d}}$ & $36.68^{\mathrm{f}}$ \\
\hline Linoleic acid (C18:2) & $33.45^{\mathrm{a}}$ & $23.54^{\mathrm{e}}$ & $25.42^{\mathrm{d}}$ & $22.66^{\mathrm{f}}$ & $32.45^{\mathrm{b}}$ & $25.77^{\mathrm{c}}$ \\
\hline Linolenic acid (C18:3) & $1.27^{\mathrm{d}}$ & $1.45^{\mathrm{cd}}$ & $1.61^{\mathrm{bc}}$ & $1.82^{\mathrm{b}}$ & $2.36^{\mathrm{a}}$ & $1.38^{\mathrm{cd}}$ \\
\hline Gadolenic acid (C20:1) & $0.14^{\mathrm{c}}$ & $0.16^{\mathrm{c}}$ & $0.15^{\mathrm{c}}$ & $0.22^{\mathrm{ab}}$ & $0.24^{\mathrm{a}}$ & $0.18^{b c}$ \\
\hline Eicosatrienoic acid (C20:3) & $0.32^{\mathrm{c}}$ & $0.51^{\mathrm{b}}$ & $0.51^{\mathrm{b}}$ & $0.65^{\mathrm{a}}$ & $0.63^{\mathrm{a}}$ & $0.31^{\mathrm{c}}$ \\
\hline
\end{tabular}

*Means with similar letters in each row are not significantly different at $5 \%$ probability level, according to Duncan's multiple range test.

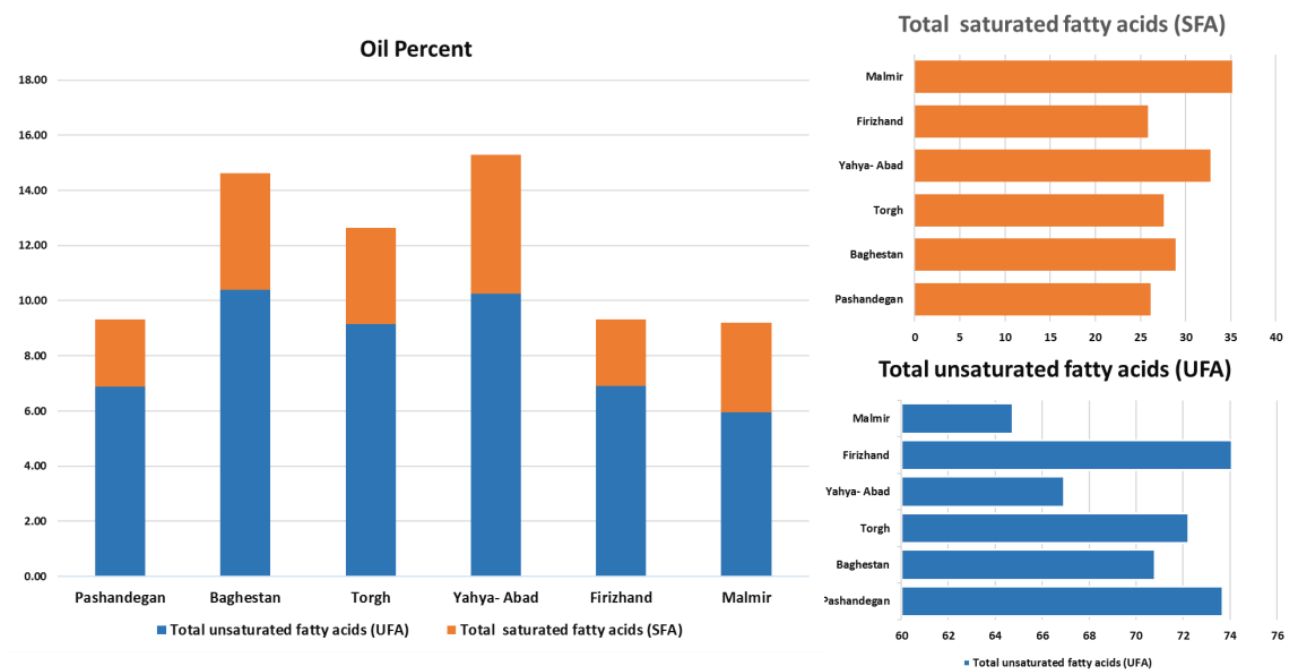

Figure 3- Oil percent, total saturated fatty acid (SFA) and total unsaturated fatty acid (UFA) composition of Sumac populations

saturated fatty acids (SFA) in current study were palmitic $(21.38-29.75 \%)$ and stearic (2.32-3.60\%) followed by arachidic acid (0.64$1.53 \%$, Table 5). In terms of unsaturated fatty acids (UFA), oleic (36.68-44.74\%), linoleic (22.66-33.45\%) and linolenic (1.27-2.36\%) acids were found as major unsaturated fatty acids (Table 5).
In all populations, the percentage of total unsaturated fatty acids (TUFA) was higher than total saturated fatty acids (TSFA). The range of total unsaturated and saturated fatty acids value was 64.75-74.08 and 25.84-35.13, respectively (Table 5). Unsaturated fatty acids can be further divided into monounsaturated (MUFAs) or polyunsaturated fatty acids (PUFAs). The range 
of PUFAs contents were $25.13 \%$ to $35.44 \%$ and the range of MUFAs were $37.29 \%$ to $45.3 \%$.

According to soil properties, important parameters are the $\mathrm{P}$ Av. $(\mathrm{mg} / \mathrm{kg}), \mathrm{Na}(\mathrm{me} / \mathrm{l}), \mathrm{K}$ $(\mathrm{mg} / \mathrm{kg})$ and soil $\mathrm{pH}$ which impressed variations of sumac. The high P. Av. value of soil was reported in Firizhand $(100 \mathrm{mg} / \mathrm{kg})$ and the lowest value were in Baghestan and Malmir (34 mg/kg). Firizhand had the high value of K. Av. (190 mg/kg), while Yahya-Abad showed the lowest $(132 \mathrm{mg} / \mathrm{kg})$. Yahya-Abad with the $965 \mathrm{me} / \mathrm{l}$ and Pashandegan with $700 \mathrm{me} / \mathrm{l} \mathrm{had}$ the highest and lowest value in $\mathrm{Na}$ (me/l), respectively.

\section{Correlation analysis}

Correlation coefficients between all fatty acid in the wild sumac populations and their quantity's relations to soil property were done. In current study, saturate fatty acid and unsaturated fatty acid $(\mathrm{r}=-1.0 ; \mathrm{p}<0.1)$, also polyunsaturated fatty acid and monounsaturated fatty acid $(\mathrm{r}=-0.60$; $p<0.005)$ is clearly negative correlated each other. According to SFAs, palmitic acid was positively correlated with stearic acid $(\mathrm{r}=0.88$; $\mathrm{p}<0.05)$ and myristic acid $(\mathrm{r}=0.86 ; \mathrm{p}<0.05)$. As stated by USFAs, oleic acid was negatively correlated with linoleic acid $(r=-0.61 ; p<0.005)$. The degree of monounsaturated fatty acid is determined by the amount of oleic acid present in the oil $(r=1.0 ; p<0.1)$. Altitude had the negative correlation with saturated fatty acid $(r=-0.94$; $\mathrm{p}<0.05)$, while had positive correlation with unsaturated fatty acid ( $\mathrm{r}=0.94 ; \mathrm{p}<0.05)$. According to correlation matrix the average annual sunshine hours (h) had the positive correlation with monounsaturated fatty acid $(r=0.58 ; \mathrm{p}<0.001)$ and negative correlation with polyunsaturated correlation $(r=-0.66 ; p<0.005)$.

In terms of soil properties, P Av. (mg/kg) content showed the positive correlation with $\mathrm{pH}$ $(\mathrm{r}=0.78 ; \mathrm{p}<0.005)$. In current study, K Av. $(\mathrm{mg} / \mathrm{kg})$ and $\mathrm{Na}(\mathrm{me} / \mathrm{l})$ contents has the significant positive and negative correlation with latitude respectively $(r=0.76 ; \mathrm{p}<0.005, \mathrm{r}$ $=-0.65 ; \mathrm{p}<0.005)$. Also, $\mathrm{Na}(\mathrm{me} / \mathrm{l})$ contents had the negative correlation with $\mathrm{K}(\mathrm{mg} / \mathrm{kg}, \mathrm{r}=$ $-0.83 ; \mathrm{p}<0.05)$. In current study, total unsaturated fatty acid had the positive correlation with K. Av. $(r=0.98 ; \mathrm{p}<0.005)$, while total saturated fatty acid had negative correlation $(\mathrm{r}=-0.98 ; \mathrm{p}<0.005)$. Also, $\mathrm{Na}$ value of soil had the positive correlation with total saturated fatty acid $(r=0.80 ; p<0.005)$ and negative correlation with unsaturated fatty acid $(r=-0.80 ; p<0.005)$. S.P percent of soil presented the negative correlation with total saturated fatty acid $\mathrm{r}=-0.90 ; \mathrm{p}<0.005$ ) whereas positive correlation with total unsaturated fatty acid $(r=0.90 ; p<0.005)$.

\section{Cluster analysis}

Cluster analysis was carried out to divide the sumac populations according to similarity and dissimilarities in fatty acids (Figure 4). Cluster analysis of sumac populations was divided to 3 main groups. The first cluster (Baghestan, Yahya-Abad and Torgh populations) included the populations with similarity level in oleic and linoleic acids. The second group (Pashandegan and Firizhand) have the lowest amount of palmitic and oleic acids. Finally, the third cluster (Malmir) have the highest amount of palmitic and stearic. 
Nayebpour \& Asadi

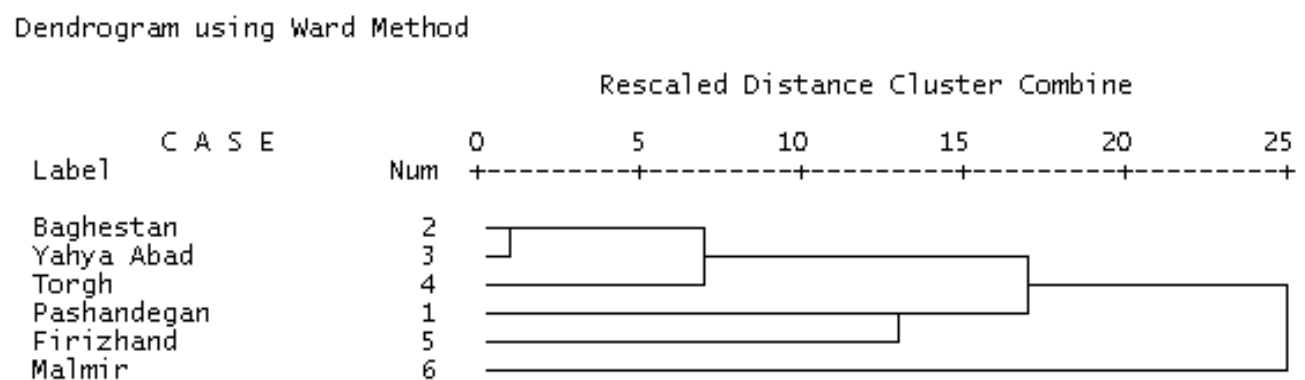

Figure 4- Cluster analysis is applied to six sumac populations (Baghestan, Yahya-Abad,Torgh, Pashandegan, Firizhand and Malmir)

\section{Discussion}

The amounts of morphological characteristics of six wild sumac fruits populations were presented in Table 3. The average weight of 100 sumac fruit in this study is lower than reported from south eastern Anatolia region of Turkey [8]. Therefore, differences sumac weight may be due to geographically affects. The range of fruit cluster length in our study were supported by the Asgarpanah et al. reports [7].

The total oils of sumac population $(9.22 \%$ to $15.33 \%$ ) which reported here are similar to those found in recent studies [12,14]. Analysis of fatty acid compositions of wild sumac populations revealed the significant differences between them. Arachidic, gadolenic and eicosatrienoic fatty acid were reported for the first time in sumac population by current study. The amounts of palmitic acid in Iranian sumac were observed the highest value in comparing other reports [1, 8, 14, 19, 6]. Differences in biochemical composition in sumac populations may be due to environmental conditions and genotype background.

In terms of unsaturated fatty acids (UFA), the similar results were reported in sumac populations from Turkey $[8,12,14]$ and also in Syrian and Chinese sumac fruit [1]. Large quantities of linoleic and linolenic acids are synthesized in plants, while they are not produced in humans and other mammals, so these fatty acids should be provided from external sources [20]. Unsaturated fatty acids are vital fatty acids which can control cholesterols and decrease the risk of heart diseases [21, 22]. Essential fatty acid, particularly the linoleic acid is a protector of cardiovascular diseases and linoleic acid regulates the low-density lipoprotein (LDL) and enhancing its clearance [23].

The high amounts of UFA, might be a health-promoting nutrient and to be interested in diet [24]. Unsaturated fatty acids can be further divided into monounsaturated (MUFAs) or polyunsaturated fatty acids (PUFAs). The lower amount of polyunsaturated fatty acid content than monounsaturated fatty acid in sumac population can be interpreted its susceptibility to oxidative degradation [25].

According to the general classification of the fatty acids of sumac fruit seed, the sequence oil was found as: MUFA $>$ PUFA $>$ SFA. The storage capacity of oils is affected by the level of polyunsaturated fatty acids due to more susceptible to oxidative degradation [14], so the 
reason of the low level of polyunsaturated fatty acid content can linked to oil storing for a long time in the sumac. In addition, the minimum amount of PUFA/SFA ratio (0.45) was described by HMSO (26) while, the ratio of polyunsaturated fatty acids to saturated fatty acids (PUFA/SFA) in all populations was varied between 0.76 (Yahyaabad) to 1.37 (Firizhan) regions (Table 5).

Seeds and fruits are main sources of oil for using in nutrition, industry and medicinal process. Different oil sources have different compounds so trying for introducing new sources of oil for human health is necessary [27]. Oil seeds have different amount of fatty acids so researches like this help us to choose the best ones for cultivating, regenerating and nutrition industry [28]. In current study, correlation coefficients showed negative correlation between saturate fatty acid and unsaturated fatty acid, also polyunsaturated fatty acid and monounsaturated fatty acid. Many factors such as soil property, temperature, light-intensity and altitude, are the most important environmental factors affecting the generation [29]. The environmental conditions such as soil properties can affect the quality and quantity of biochemical parameter plants [30]. Monounsaturated fatty acid is importance to human health and due to its close relationship with the geographical growing area may be considering as importance factor for future study [31]. Genetic and environmental factors influence on seed fatty acids compositions [32, 33]. According to soil properties of sumac population and correlation analysis between them, the high value of K. Av. and low amount of $\mathrm{Na}$ can be cause to higher unsaturated fatty acid in populations. Furthermore, high value of saturated fatty acids may be under the influence of the low value of K. Av. and high amount of Na. Therefore, soil property affected concentration of nutrients in plant and their medicinal values [34].

\section{Conclusion}

In the present study, we evaluated the fatty acids composition of some wild Iranian sumac populations. There are significant differences among the fatty acid compositions of sumac oil. The average amounts of the major fatty acids are including: oleic $(40.45 \%)$, linoleic (27.22\%), palmitic (24.94\%), stearic $(2.74 \%)$, linolenic $(1.65 \%)$, arachidic $(1.13 \%)$, gadolenic $(0.19 \%)$, eicosatrienoic $(0.49 \%)$, palmitoleic $(0.43 \%)$ and myristic acid $(0.34 \%)$. Based on results, the sumac oil of all populations have high amount of unsaturated and low amounts of saturated fatty acids in order to improve human health. This advantage confirms the use of sumac oil in diet as a good source of unsaturated fatty acids. On the other hand, this variation in wild population can be exploited by breeders to expand the food production, meanwhile increasing the nutrient values as a food resource additive. To sum up, the study suggests that the genetic and environmental factors can influence on seed fatty acids compositions in sumac fruit.

\section{References}

1. Kossah R, Nsabimana C, Zhao J, Chen H, Tian F and et al. Comparative study on the chemical composition of Syrian sumac (Rhus coriaria L.) and Chinese sumac (Rhus typhina L.) fruits. Pakistan Journal of Nutrition 2009; 8 (10): 1570-4. 
2. Nasar-Abbas SM and Halkman AK. Inhibition of some foodborne bacteria by alcohol extract of Sumac (Rhus coriaria L.). Jounal of Food Safety 2004; 24: 257-67.

3. Bahar $B$ and Altug T. Flavour characterization of Sumac (Rhus coriaria L.) by means of GC/MS and sensory flavour profile analysis techniques. International Journal of Food Properties 2009; 12: 379-87.

4. Morshedloo MR, Maggi F, Neko HT and Aghdam MS. Sumac (Rhus coriaria L.) fruit. Essential Oil Variability in Iranian Populations. Industrial Crops and Products 2018; 111: 1-7.

5. Gharaei A, Khajeh M, Ghaffari M and Choopani A. Iranian Rhus coriaria (sumac) essential oils extraction. JEOBP. 2013; 16 (2): 270-3.

6. Ünver A and Özcan MM. Determination of physical and chemical properties of some sumac (Rhus coriaria L.) fruits growing wild in Turkey. Journal of Selc. UK University Agriculture Faculty. 2006; 20 (40): 111-6.

7. Asgarpanah J and Saati S. An overview on phytochemical and pharmacological properties of Rhus coriaria. RJP. 2014; 1 (3): 47-54.

8. Kizil $S$ and Turk M. Microelement contents and fatty acid compositions of Rhus coriaria L. and Pistacia terebinthus L. fruits spread commonly in the south eastern Anatolia region of Turkey. Natural Product Research. 2010; 24 (1): 92-8.

9. Ozcan $M$ and Haciseferogullari HA. Condiment Sumac (Rhus corriaria L.) fruits. Somephysico-chemical properties. Bulgarian Journal of Plant Physiology 2004; 30: 74-84.

10. Ardalani H, Moghadam MH, Rahimi R, Soltani J, Mozayanimonfared A and et al. Sumac as a novel adjunctive treatment in hypertension: a randomized, double-blind, placebo-controlled clinical trial. Rsc Advances 2016; 6 (14): 11507-12.

11. Abu-Reidah IM, Ali-Shtayeh MS, Jamous RM, Arraez-Roman D and SeguraCarretero A. HPLC-DAD-ESI-MS/MS screening of bioactive componentsfrom Rhus coriaria L. (Sumac) fruits. Food Chem. 2015; 166: 179-92. 12. Matthaus B and Özcan MM. Fatty acid composition, tocopherol, and sterol contents of sumac (Rhus coriaria L.) fruit oils. The European Journal of Lipid Science and Technol. 2015; 117: 1301-2.

13. Lai J, Wang H, Wang D, Fang F, Wang F and et al. Ultrasonic extraction of antioxidants from Chinese sumac (Rhus typhina L.) fruit using response surface methodology and their characterization. Molecules 2014; 19: 9019-32.

14. Dogan $M$ and Akgul A. Characteristics and fatty acid compositions of Rhus coriaria cultivars from Southeast Turkey. Chemistery of Natural Compounds 2005; 41: 724-5.

15. Ünver A and Özcan MM. Fatty acid composition of seed and pericarp of sumac (Rhus coriaria L.) grown wild in different regions of Turkey. JFAE. 2010; 8 (1): 31-3.

16. Miransari M, Bahrami HA, Rejali $F$ and Malakouti MJ. Using arbuscular mycorrhiza to alleviate the stress of soil compaction on wheat (Triticum aestivum L.) growth. Soil Biology and Biochem. 2008; 40 (5) 1197-206.

17. AOAC. Official methods of analysis. Association of Official Analytical Chemists, 14th Edition, Arlington: 1984, USA.

18. Demchik S, Rajangam A, Hall $J$ and Singsaas E. Fatty Acids, Carbohydrates and Total Proteins of Wild Sumac (Rhus typhina L.) Drupes from the Upper Midwest of the United 
States. American Journal of Essential Oils and Natural Products 2015; 3 (2): 30-4.

19. Wang $S$ and Zhu F. Chemical composition and biological activity of staghorm sumac. Food Chem. 2017; 237: 431-43.

20. Horrocks LA and Yeo YK. Health benefits of docosahexaenoic acid (DHA). Pharmacological Res. 1999; 40 (3): 211-25.

21. Foran JA, Good DH, Carpenter DO, Hamilton MC, Knuyh BA and et al. Quantitative analysis of the benefits and risks of consuming farmed and wildsalmon. Nutrition 2005; 135: 2639-43.

22. Park S and Johnson MA. Awareness of fish advisories and mercury exposure in women of childbearing age. Nutrition J. 2006; 64: 250-6.

23. Wijendran V and Hayes KC. Dietary n-6 and n-3 fatty acid balance and cardiovascular health. The Annual Review of Nutrition 2004; 14 (24): 597-615.

24. Fernandes L, Casal S, Cruz R, Pereira JA and Ramalhosa E. Seed oils of ten traditional Portuguese grape varieties with interesting chemical and antioxidant properties. Food Research International. 2013; 50: 161-6.

25. Hsieh RJ and Kinsella JE. Oxidation of polyunsaturated fatty acids: mechanisms, products, and inhibition with emphasis on fish. In Advances in Food and Nutrition Research (Academic Press). 1989; 33: 233-341.

26. HMSO. U. K. Nutritional aspects of cardiovascular disease. Report on Health and Social Subjects No 46. London: 1994.

27. Iranmanesh $\mathrm{Y}$ and Jahanbazi Goujani $\mathrm{H}$. Comparison of fatty acid composition of fruit oil from acom (Persian oak), Pistacia atlantica Desf. and four wild almond species. Iranian Journal of Medicinal and Aromatic Plants 2016; 33 (2): 325-37.
28. Okay Y. The Comparison of some Pistachio Cultivars Regarding their Fat, Fatty acids and Protein Content. Gartenbauwissenschaft. 2002; 67 (3): 107-113.

29. Zakerin A, Ahmadi E, Fasihi-Ramandi M, Abdollahi S and Molazadeh A. The effects of ecologic condition on antimicrobial activity of endemic herbal extracts in Fars province. Journal of Fasa University of Medical Sciences 2015; 5 (1): 111-9.

30. Mohammadi M, Asadi-Gharneh HA. How geographical differences mayaffect the uptake of nutrients by the wild populations of pennyroyal (Mentha longifolia (L.), Huds). Catena 2018; 165: 173-7

31. Carvalho CC, Marques MP, Hachicho $N$ and Heipieper HJ. Rapid adaptation of Rhodococcus erythropolis cells to salt stress by synthesizing polyunsaturated fatty acids. Applied Microbiology and Biotechnol. 2014; 98 (12): 599-606.

32. Javanmard $M$, Asadi-Gharneh $H A$ and Nikneshan P. Characterization of biochemical traits of dog rose (Rosa canina L.) populations in the central part of Iran. Natural Product Res. 2017; 32: 14, 1738-43.

33. Mostafavi S, Asadi-Gharneh $\mathrm{HA}$ and Miransari M. The phytochemical variability of fatty acids in basil seeds (Ocimum basilicum L.) affected by genotype and geographical differences. Food Chem. 2019; 276: 700-6.

34. Cindrić AM, Garnier C, Oursel B, Pižeta I and Omanović D. Evidencing the natural and anthropogenic processes controlling trace metals dynamic in a highly stratified estuary: The Krka River estuary (Adriatic, Croatia). Marine Pollution Bulletin. 2015; 94 (1-2): 199-216. 